\title{
EVALUATION OF THE CAPACITY OF RISK CARRIERS BY MEANS OF STOCHASTIC-DYNAMIC PROGRAMMING
}

\author{
T. Pentikëinen and J. Rantala
}

\section{INTRODUCTION}

The Ministry of Social Affairs and Health, being the Supervising Office of Insurance in Finland, has established a special working group to investigate the problems involved with the solvency of insurers. A report will be compiled in a near future. The capacity of risk carriers is one of the problems dealt with, and it will be preliminarily reviewed in this paper.

The problem was treated by the working group parallelly by means of

1. an empirical approach observing actual fluctuations in underwriting gains of insurers, and

2. a theoretical approach, constructing a stochastic-dynamic model and studying its behaviour, especially its sensitivity to numerous background factors.

First the methods of investigation are described and their application is then demonstrated using some numerical data. Because a comprehensive report will be published by the working group separately, only the main schedule is given. For the same reason the consideration is limited here to stochastic risks, omitting the fact that the solvency of an insurer is also jeopardized by numerous "non-stochastic" risks such as failure in investments, political interference of the authorities, mismanagement of the company, or misappropriation of its property.

\section{STOCHASTIC-DYNAMIC MODEL}

The state of an insurer is defined by means of state variables such as the volume and mix of the portfolio, reserves, etc. Then a number of transition equations are constructed to control the incoming and outgoing money flows, as shown in the attached schedule. The difference $\Delta U$ between these flows, the underwriting profit or loss, is accumulated into a risk reserve $U . U$ is equivalent to the concept of the solvency margin, if underevaluations of assets and overevaluations of liabilities (e.g. fluctuation reserves, catastrophe provisions, safety margins, etc. in underwriting reserves) are included in it.

Numerous exogenous and endogenous factors can be taken into account, as referred to in the schedule. 
The model is dynamic in that it can bc made self-correcting ("adaptive"). For example, if the solvency ratio $U / B$ is high, the level of the net retentions of reassurance can be increased, and vice versa. If the profitability is good, then more efforts can be allocated for sales promotion. If the state of the insurer is becoming critical, then cconomizing in administration, deduction of sales costs, etc. can be programmed, as can an increase in premium rates. Different kinds of business strategies can be experimented with, especially if the model is to be used to prognosticate the state and future development of an insurer for the insurer's own use. Such strategies could be aimed at increasing market shares by means of sales campaigns, by means of competitive reductions in premiums, etc. However, in the work of the Finnish study group these features were not taken into account; instead attention was given more to finding general conditions on which the solvency may depend.

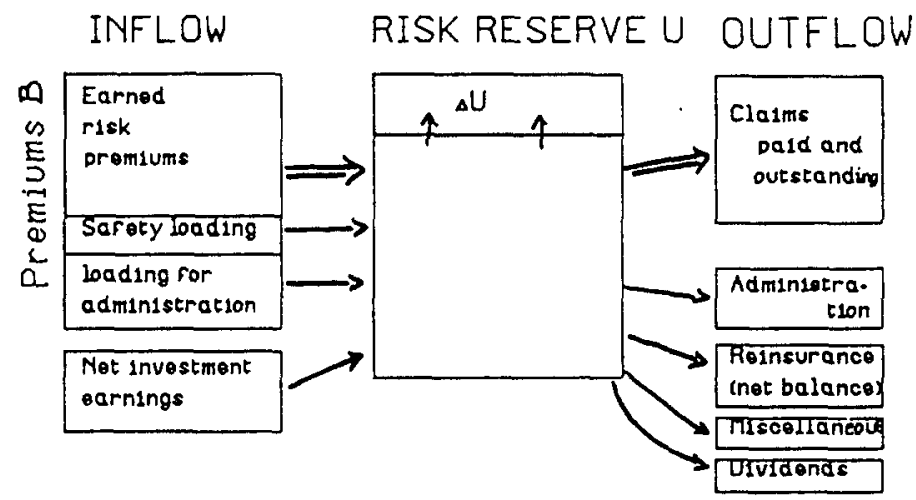

Variables and assumptions

State variablos \& parameters

- Portrolto mix, branches $1=1,2, .$.

- Clasm sizedr

- Volume indicetors $n=n_{2}+n_{2}+\ldots$

(expected number of cla1ms)

+ Reserves

- Assets

\section{Exogenour ractors}

- short perlod rluctuation of

the basic orobabilities

+ Long period business cycles

- Inrlation

- steady rate $1_{x}$

- shock impulsies $\Delta 1_{x}$

- Market condition:

- roal growth or the

portroliog

- salos responso etc.

- Rate or interest $i_{n}$
Business strategies

- Rates or premiums - saroty loadings

- Reinsuranco - net retentions $M_{j}$ - Sales efforts, administr.

- Dividends

- Sarery lovel iruin probabillty $c$ and time span $T$ ) 
The model is stochastic in that the claims (and possibly some other variables as well) are assumed to vary stochastically. For the purpose a random number generator was constructed to simulate the aggregate amount of claims. Four levels of stochasticity were assumed:

1. The number of claims varies at random (counting process).

2. The clain size $\zeta$ varies at random; distribution functions are given for each portfolio section $S_{j}(z)$. These functions also depend on the reassurance and its net retentions $M_{j}$, where $j$ indicates the section (branch) of the portfolio.

3. Short term variation. The expected number of claims $n_{j}$ vary at random from year to year (being fixed inside each calendar year). Standard deviations $\sigma_{j}$ and skewnesses $\gamma_{j}$ of the fluctuations in basic probabilities are given input parameters. One reason for this type of variation may be

- weather conditions.

4. Business cycles. The basic probabilities are also subject to long period variations. Business cycles are introduced into the model by means of autoregression rules or by deterministically or "half-deterministically" randomizing the phase of the cycle. Business cycles are caused by general economic cycles (booms, recessions), by cycles generating mechanisms in the insurance market, by inflation, etc.

Fig. 1 shows an example of the random flow (realisation of the process or a "sample path") for a time span of 25 years.

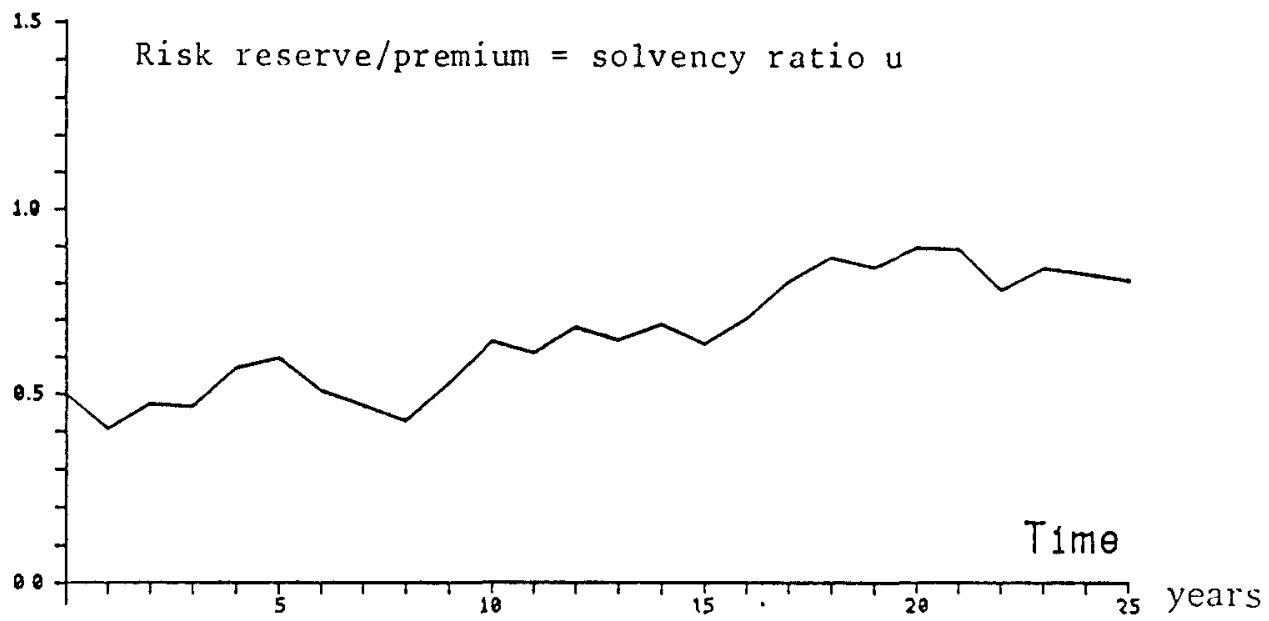

Fig. 1. A realisation of the business flow process.

Instead of taking the absolute amount of the solvency margin $U$ as the main indicator, it seems advisable to take the relative amount, the solvency ratio, denoted by $u=U / B$, wherc $B$ is the premium income (cf. schedule). 
Relative variables of this kind with dimension o in respect of monetary unit are not clirectly affected by inflation as are the absolute amounts. Hence they are suitalle variables for long-term prognoses where the value of money is not assumed to be constant.

Following the iclea of the Monte Carlo method the simulation is repeated numcrous times. $\Lambda$ bundle of sample paths is thus obtaincd, as shown in Fig. 2.

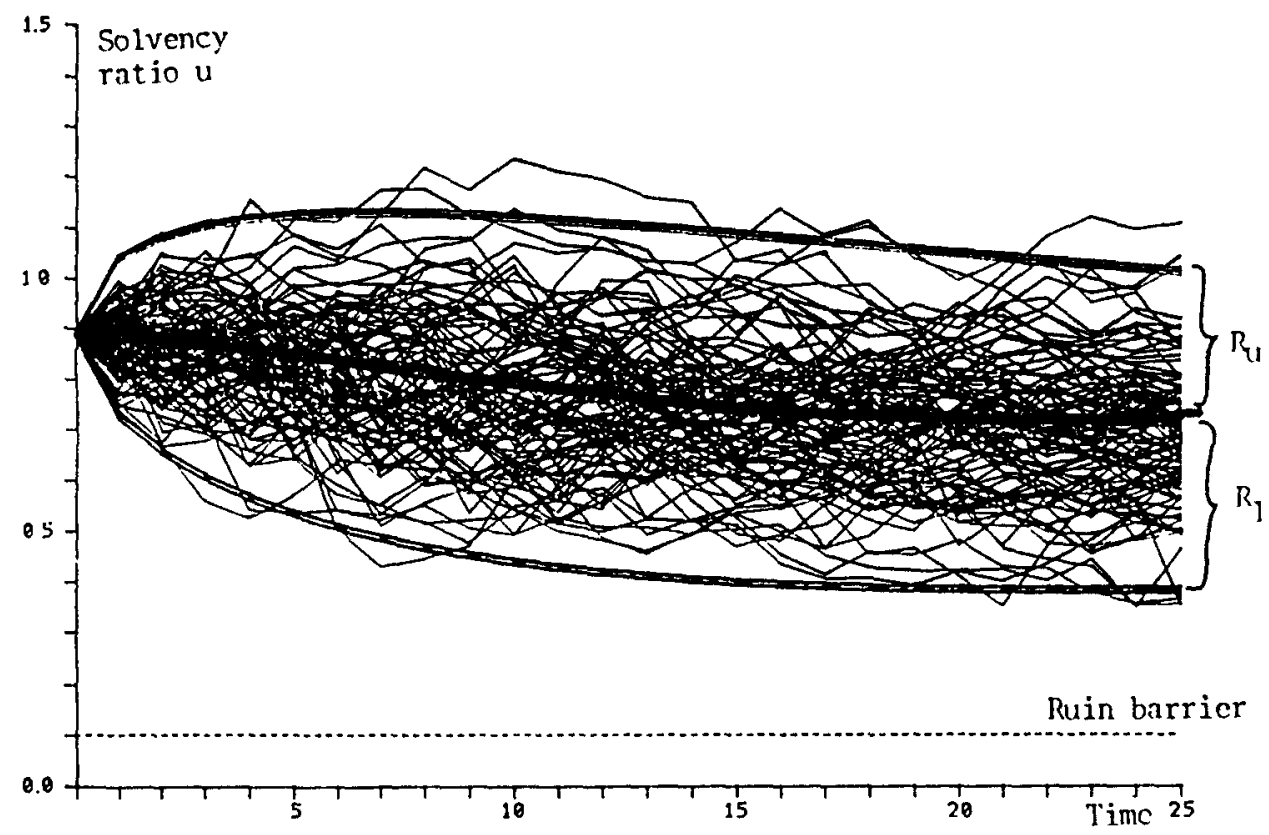

Figg 2. A bundle of realisations of an insurer's businese flow process

$\Lambda$ "stochastic bunclle" like that in fiig. 2 is an important tool in analysing the solvency of an insurer. The shape and position of the bundle make it possible to draw conclusions on the solvency and other features of the process. If the bundle is safely over the ruin barrier (c.g. the legal minimum amount of solvency margin) it indicates a solvent state.

\section{Analytic method}

It is often possible as a short cut approach to compute directly the middle line of the stochastic bundle plotted in Fig. 2. The confines of the bundle are also directly computable, when the probability is given, according to which the realizations will lic between the confincs. The breadth of "the stoclastic bundle" is denoted hy the range variables $R_{u}$ and $R_{l}$ as secn in Fig. 2. Due to the skewness of the claims process they may not necessarily be equal.

From the middle line of the stochastic. bundle and from the ranges $R$ it is 
possible to derive an upper limit and a lower limit to the T-year ruin probability, which can be conveniently used as one of the solvency indicators. The method was described by PENTIKÏINEN (1978a) and an improved method will be published by $J$. RanTala in the near future.

The configuration of Fig. 2 can be used in constructing an evaluation for the minimum solvency ratio. This approach is illustrated in Fig. 3. The computer can be programmed to move the stochastic bundle of Fig. 2 in the vertical direction so that its lower confine just touches the ruin barrier. Then the position of the initial solvency ratio indicates the necessary minimum amount of the solvency margin. It is another useful indicator in solvency considerations.

Details of the model were described by PENTIKÄINEN (1978a). However, for the present solvency investigation they have been considerably further developed and will be published separately by the working tcam, as already mentioned above.

Numerous references to model building can be found in the Transactions of the 1980 Congress of Actuaries as well as in the publications in the reference list. The lecture by W. JEwELL on models is worthy of special mention, together with the list of references presented.

A comprehensive model has been built by Galitz et al. at the University of North Wales in co-operation with the Geneva Association.

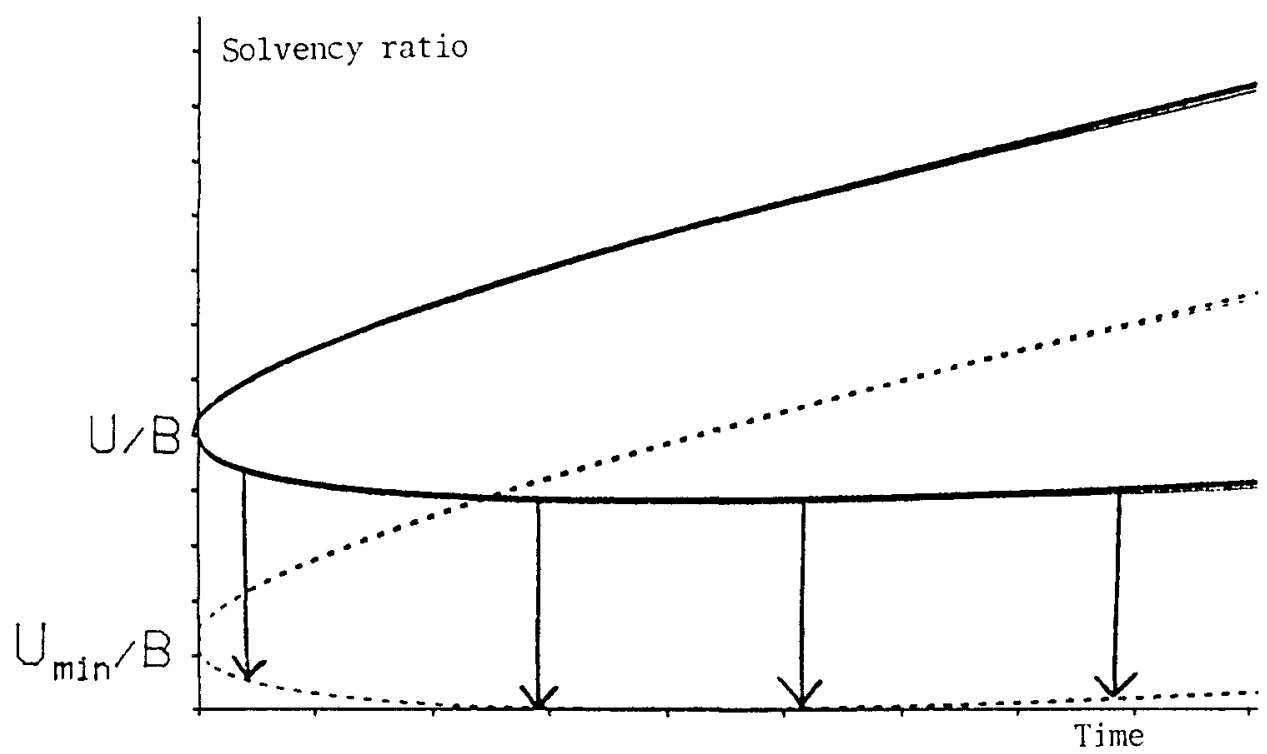

Fig. 3. Construction of a minimum solvency ratio $U_{m i n} / R$ The stochastic bundle is moved down so as to just touch the zero level, which for the sake of simplicity indicates the ruin barrier. 

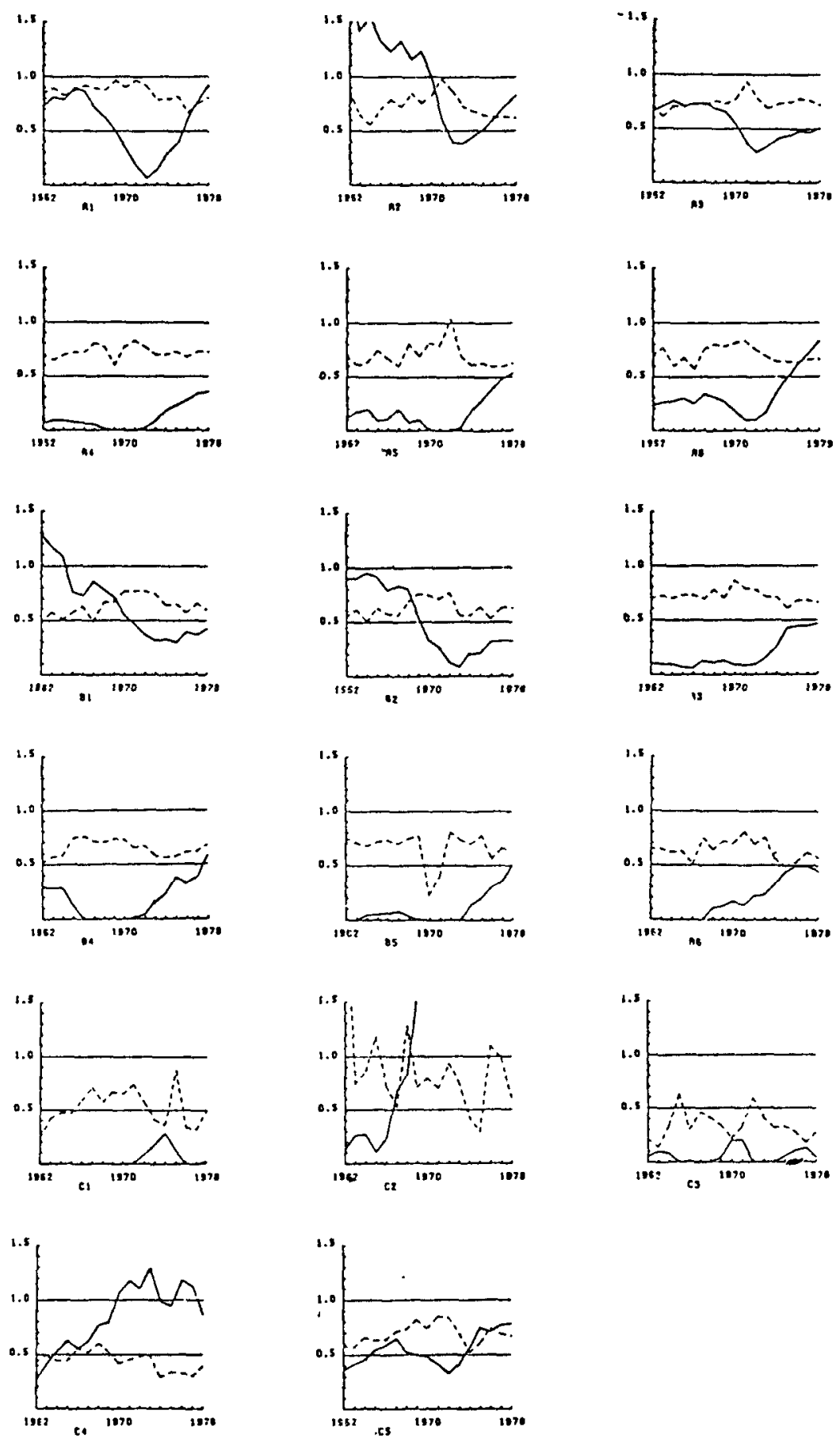

Fig. 4. An example of the business flow of 17 Finnish insurance companies. Solid line $=$ fluctuation reserve/premiums (indicating loce solvency ratio $u$ ) and dotted line $=$ claims ratio $X / B$. The data were received from the Supervising Office. The solvency margins are not published and therefore, for the sake of anonymity, only the codes of the companies are given. 


\section{EMPIRICAL APPROACH}

To test the goodness of fit of the model and to calibrate its parameters, a large amount of data from the actual flow of business of all Finnish non-life insurance companies was collected. An example of the data is given in Fig. 4. The dotted line represents the claims ratio, i.e. the aggregate claims/earned premiums on the company's own retention. The solid line is intended to indicate the flow of the solvency ratio. The total amounts of the solvency margins were not available, and so instead the so-called fluctuation (equalization) reserve, which is a specialty prescribed in the Finnish Insurance Company Act, was used. The accumulated profit from risk business has to be transferred to this reserve, and the loss from underwriting business subtracted from it. Hence the reserve's flow indicates the variations of the accumulated underwriting profit $( \pm)$ quite well. Only in cases where the equalization reserve was occasionally cxhausted to zero does this idea not function. In these cases the solvency margin was entircly composed of the company's own bookcd capital, to which are added hidden reserves like underevaluation of assets, etc.

Fig. 4 may be unique in that the unsmoothed result is genuinely given. It may deviate from conventional published flow charts in that no significant smoothings (or manipulations) are present.

One pronounced gencral feature can be found from the plotted curves. There are periods when the solvency ratios go either up or down in several consecutive years, i.e. some kind of business cycles appear, the shape of which are very

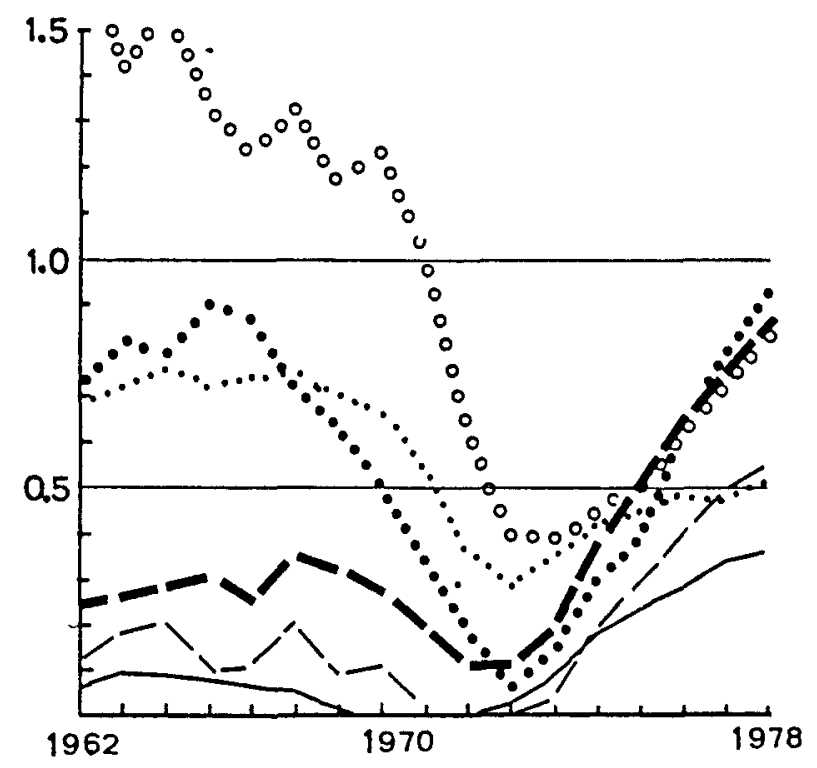

Fig 5 The flow of the risk reserve $U / B$ of six large non-life companies. 


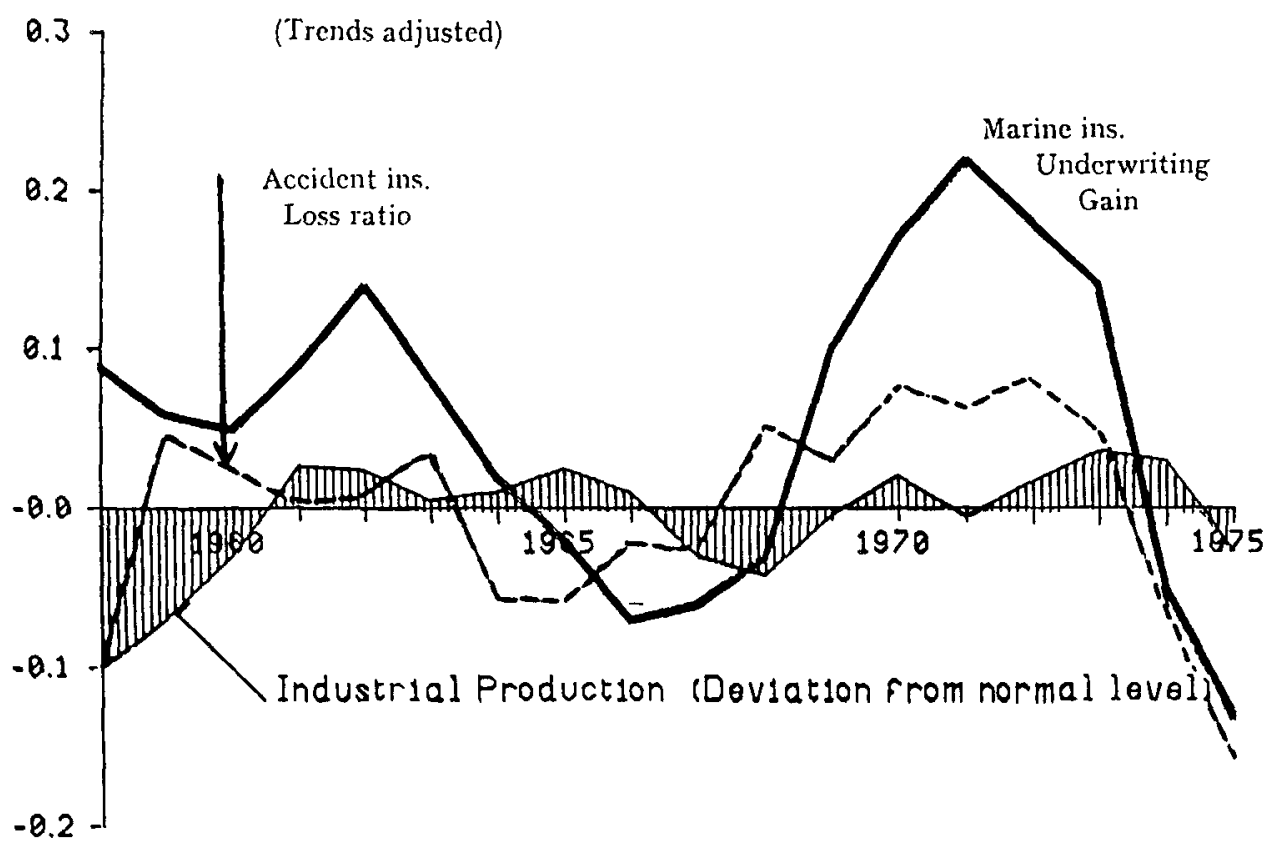

Fig. 6a. The joint marine and employment accident business of all Finnish insurance companies. Deviation from the average levels. Note the clear correlation with the general economic cycles, which are indicated by the industrial production index.

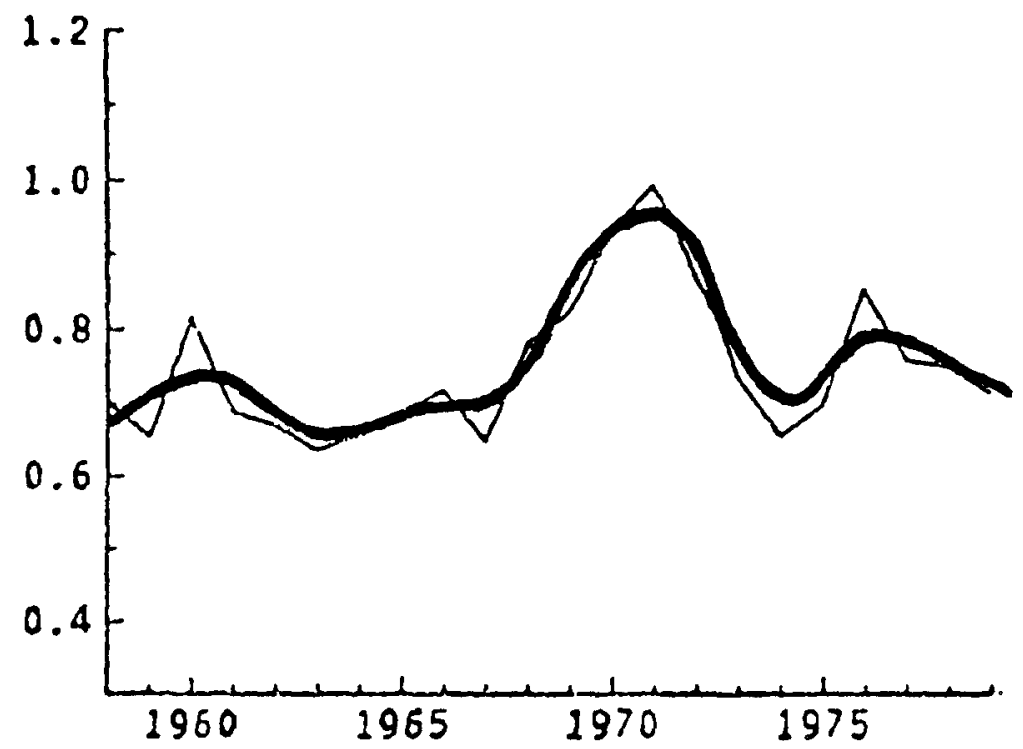

Fig. 6b. Loss ratio of the joint business of all Finnish insurance companies concerning motor third party liability. The actual and smoothed data. The smoothed data can be interpreted to represent the long period variations and the deviation of the actual data from the smoothed data mainly the short period variation. 
similar to the well-known business or growth cycles known in the national economy and to many industrial or commercial enterprises. To show this more clearly the flow of the solvency ratio $u$ of six large companies is included in the same figure (Fig. 5). The business cycles of the companies are obviously synchronized in time.

Figs. $6 \mathrm{a}$ and $6 \mathrm{~b}$ show the joint business of all Finnish insurance companies. Due to the large volume of material the ordinary Poisson fluctuation is negligible in size and the variations from year to year are caused by long-period business cycles and by short-term variation of the basic probabilities. In Fig. $6 \mathrm{~b}$ the smoothed flow describes long-period business cycles and it can be assumed that deviations in the actual values from it are caused mainly by short-term variations.

The mechanism behind business growth is obviously quite a complicated one and as yet not well known. One of the reasons for this phenomenon is clearly the reflection of the normal growth cycles in national economies. A boom gives rise to increased loss ratios for many non-life branches owing to the increased activity in industry and other sectors. A recession can have the opposite effect. The influence of business cycles varies from sector to sector. Another reason is a general mechanism characteristic of free markets generally, and is by no means confined to insurance markets. Good profitability stimulates competition, new enterprises appear and the market shows clear signs of competitive premium reductions and increased sales promotion expenditure. So this favourable market is soon "spoiled" and downswing can be expected. Due to the reluctance of the market mechanism this swing will continue for several years until poor results again compel the insurers to increase rates and reduce competition, thus making the market ready for a new upswing.

Obviously other backgrourd factors also exist, and these may differ in time and space.

A considerable amount of literature has been published concerning the general econometric models, growth cycles, etc. It is astonishing that, the corresponding phenomena for insurance markets have received little attention. However, some recent notable works by HELTEN, KARTEN and BECKER can be referred to (cf. references).

The purpose of the empirical approach was, of course, to find guidance to assist with the theoretical approach and also to calibrate the model parameters so as to get a model capable of realistically simulating real world phenomena and of explaining the actual business flow behaviour and forecasting the range of fluctuations. The importance of the business cycles was stressed, as was the necessity of incorporating them into the model. 


\section{APPLICATIONS}

\subsection{Some general comments; a standardized insurer}

The Finnish working group has produced a great collection of applications aimed at monitoring the complicated problem of solvency. It is not possible to review this side of the work here. The applications given in the following are intended only to demonstrate how the model drafted above can be applied.

The number of variables and assumptions involved in the model is quite large. This makes it difficult to get any idea of how the numerous variables affect the solvency and other behaviour of the model, and especially difficult to determine their interdependences. One solution to this "communication difficulty" was to construct a special "standard instirer", which corresponds to a typical, average insurance company. The basic data and the solvency indicators were calculated for this particular case. Then one or more of the background variables, such as the size of the insurance company, the level of reassurance, inflation and numerous others were taken, in turn, as moving variables, whereas all the others were fixed. In this way it was possible to get a concept of the sensitivity of the model to various background factors.

One critical qucstion concerning the standard insurer approach is whether

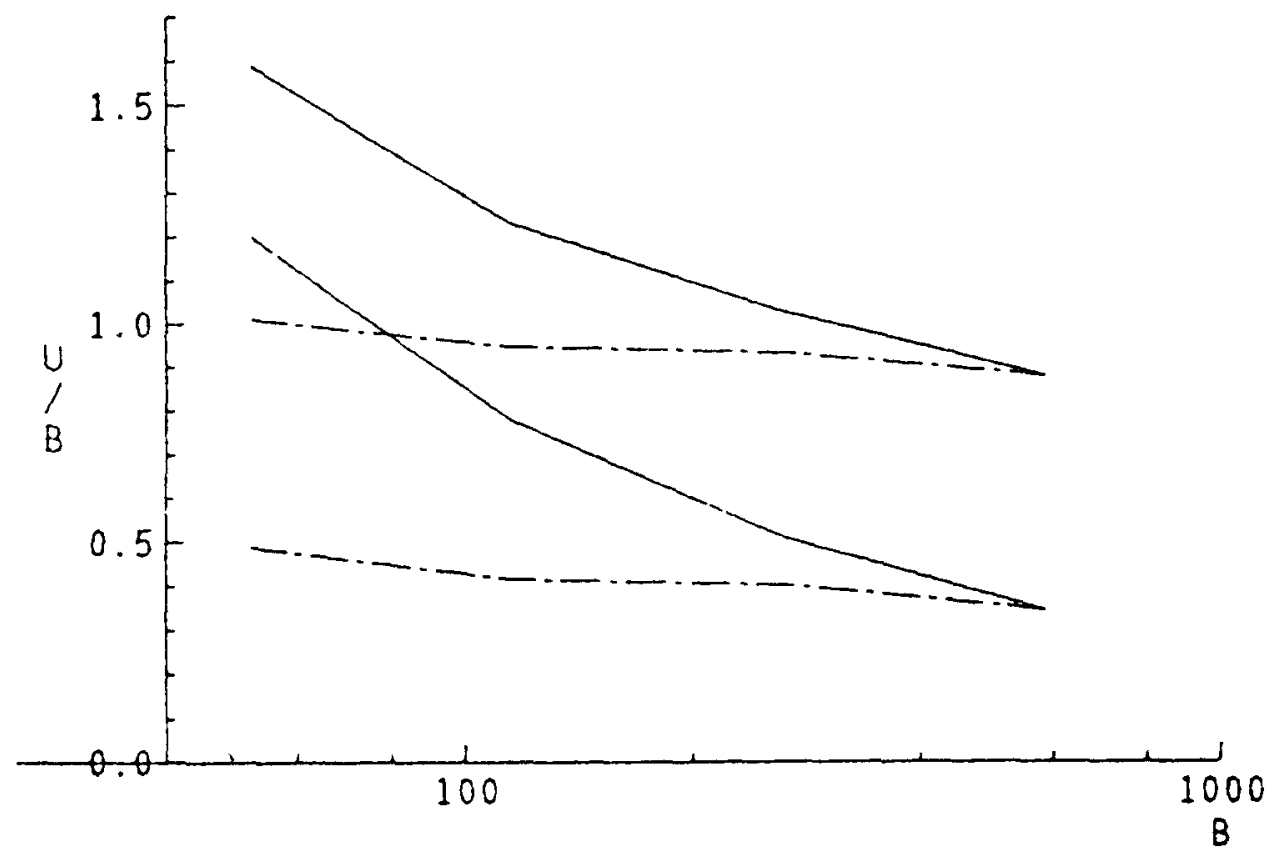

Fig. 7. Munimum solvency ratio as a function of premium incone B (standard insurer). Solid lime: Net retention constant. Dotted line: According to a specific scale, net retention increases with premium income $B$ (in millions of monetary unit). Upper curves: business cycle included. Lower curves: business cycle excluded. Ruin barrier is $0.1 . B$ and time span 10 years. 
or not the actual circumstances of insurers of different sizes and types are too far from each other to be described by one standard case only. For example, if the portfolio is large, then the risk fluctuations are expected to be smoothed well, but for a small portfolio they can predominate. This can be seen in Fig. 7 .

The minimum solvency margin, as illustrated in Fig. 3, was calculated for the standard insurer. However, the volume of premium income $B$ on the company's own retention (including safety loadings and loading for administrative expenses) was changed. As the solid lines show, the minimum solvency margin depends greatly on the size of the company. This is especially true in the case where the business cycles were not assumed (lower line). However, in practice the level of net retentions in reassurance is adjusted according to the size of the insurer. Normally, large companics have considerably larger net retentions than small ones. For this reason a special scale was constructed according to which the net retention was dependent on the size of the company. An important observation was that the size of the company no longer had any significant influence (dotted line). This observation justified the use of one standard insurer as "a yardstick" even if all results are to be tested separately and the standard insurer method can give only preliminary hints of solvency structures.

\subsection{Inflation}

Another example of an application considered here is the influence of inflation. It is advisable to discuss separately the cases where the rate of inflation $i_{x}$ is assumed to be steady, i.e. the same from year to year, and where the rate varies from year to year.

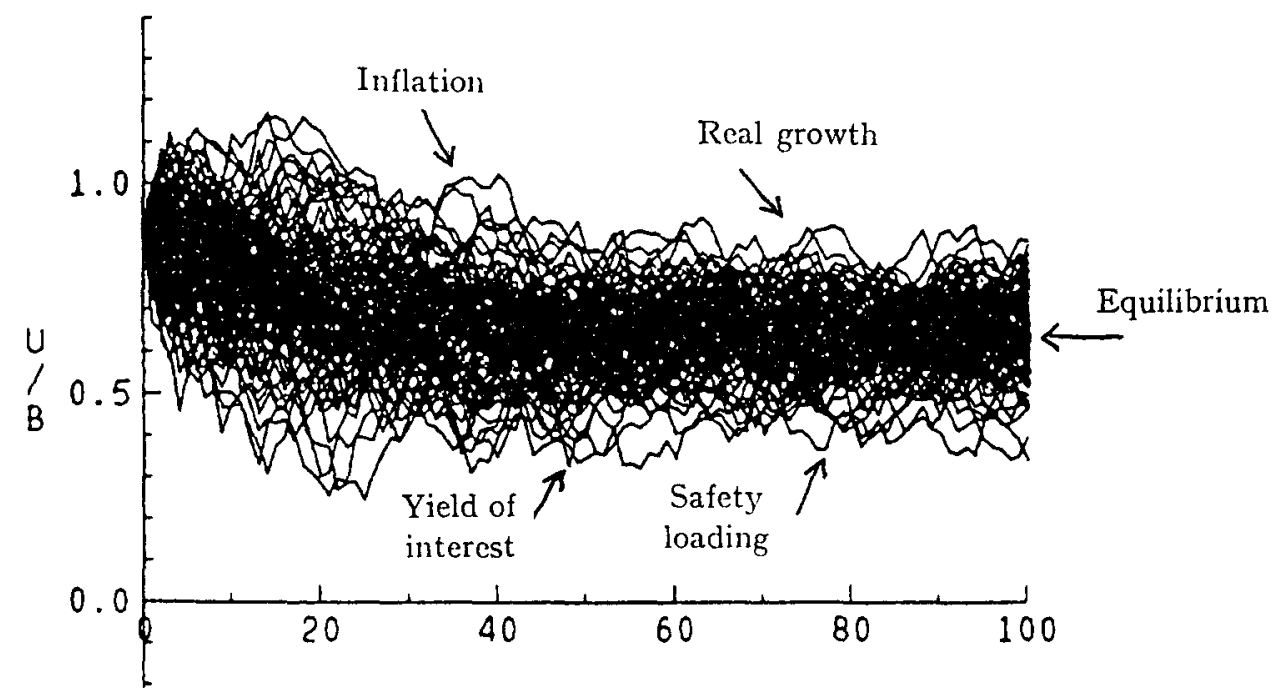

Fig. 8. Influence of a steady inflation and other factors. 
The influence of a steady inflation rate and some other most important background factors to the solvency ratio is shown in Fig. 8 , which was generated by means of the Monte Carlo method.

The real growth in the portfolio is mcasured by the growth rate $i_{g}$, which is defined as the real growth in premium volume $B$. Hence the nominal increase in $B$ is composed of both the inflation and real growth increments

$$
B(t+1)=\left(1+i_{x}\right) \cdot\left(1+i_{g}\right) \cdot B(t)
$$

where $t$ is the time in years.

Another background factor is the safety loading $\lambda$. It is composed of the conventional safety loading in premiums added by the yield of interest for the underwriting reserve, which is available to reinforce the total underwriting gain of the insurer.

In addition, the yield of interest, rate $i_{n}$, added to the solvency margin was also taken into account.

The configuration shown in Fig. 8 gives rise to some observations of interest. The stochastic bundle of realizations is essentially different from that which is customary in conventional risk theory. Normally, the standard deviations and hence the breadth of the bundle continuously increase as time $t$ increases. It is also well known that the final (for a infinite time span) probability of ruin can be less than 1 only if the bundle, i.e. solvency ratio $u$, tends to infinity. Here the bundle quite obviously has a finite asymptotic range and a certain equilibrium level. This can be explained by means of the background factors mentioned above as follows:

As shown in Fig. 8 there are actually four principal forces in action. Inflation continuously reduces the solvency ratio, because it causes an increase in the denominator of $u=U / B$, i.e. $B$ is nominally growing. For the same reason real growth also reduces the solvency margin and forces the solvency ratio down. On the other hand, the yield of interest continuously increases the solvency ratio, as does the safety loading $\lambda$ (if it is positive, as of course it must be for any sound business in the long run). The combined effect of inflation, real growth and interest is proportional to the actual size of $u$, whereas safety loading is proportional to the business volume $B$. Hence in the upper sector of the figure the former forces are strong and in the lower sector weak, whereas the safety loading effect is the same throughout. If the multiplicative joint effect of inflation and real growth is larger than that of the yield of interest, i.e.

$$
\left(1+i_{x}\right) \cdot\left(1+i_{g}\right)>1+i_{n},
$$

then there is always a certain equilibrium level where these forces are equal. If the actual size of $u$ is above this equilibrium level, then the forces pressing down are stronger. The reverse is true if it is below the equilibrium level. 
Honce there is a compressing drift against this equilibrium level, which explains the general behaviour of the process.

A rule of thumb is that the real growth of non-life business is about $1.5 x$ the growth rate of $G N P$. Hence it generally varies in range $4-8 \%$ per annum (the Finnish figure for the past 17 years is $6 \%$ ). The rate of inflation usually varies in different countries between 5 and $15 \%$. Normally the nominal actual average yield of interest does not come up to the level of the multiplicative joint effect of inflation and real growth, i.e. the condition (4.2.2) may be valid, at least in the long run as far as we can sec. If it is not, then the structure of the process is essentially different from that shown in Fig. 8 , and the bundle is moving to infinity!

It can be shown that the equilibrium level is

$$
E u=\frac{\lambda}{1-r_{r n}}
$$

where $\lambda=$ the safety loading (see p. I2) and

$$
\begin{aligned}
r_{r n}= & \frac{1+i_{n}}{\left(1+i_{g}\right) \cdot\left(1+i_{x}\right)} \\
= & \text { the relative interest factor relative to the nominal growth of } \\
& \text { the premium income. }
\end{aligned}
$$

Using the average figures of the Finnish companies for the years 1964-1979 we get the equilibrium level $66 \%$.

Without going into the matter more deeply we may conclude that the four background factors shown in Fig. 8, inflation included, are significant for any solvency consideration.

The actual rate of inflation varies from year to year. Hence the assumption of its constant value was a simplification. This assumption is relaxed in Fig. 9 .

Introduction of a shock inflation into the model produced drastic effects, as can be seen. The effect of varying inflation depends, among other things, on the assumptions of how claims and premiums will react to it. If an unexpccted shock inflation appears, the insurers are not sufficiently prepared to change premium rates immediately. This effect is escalated by the fact that the premiums are normally collected at the beginning of the insurance period and correspond (in the best case) to the expected level of inflation during the forthcoming period. If the actual rate of inflation exceeds the expected (if any) amount, claims and expenses increase almost immediately, though premiums can only be corrected after some time lag. In the example given in Fig. 9 this time lag was assumed to be two years. Fig. 9 demonstrates the use of the stochastic-dynamic model as a "sensitivity analyser". Only one realization was generated. The rate of inflation in two particular years was varied and the 


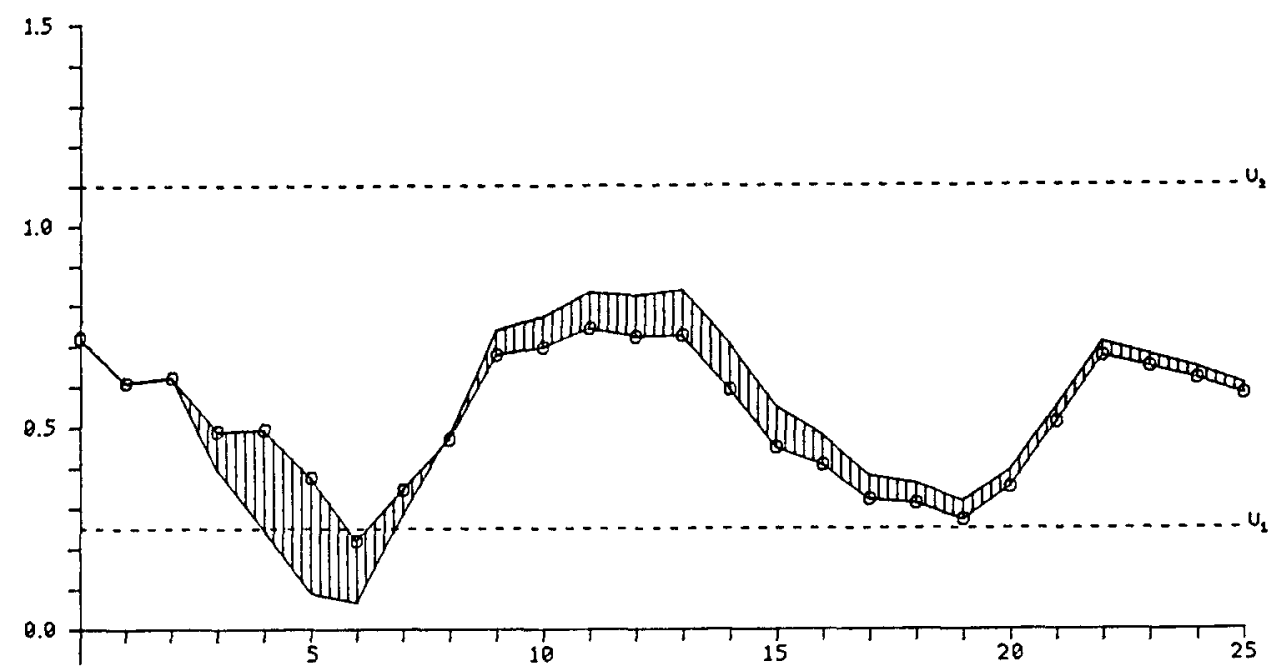

Fig. 9. Solid line with circles: Only a steady inflation rate of $8 \%$ /annum assumed. Weaker line. In addition a shock inflation rate of $20 \% /$ annum in years 3 and 4 assumed. The shaded area marks the difference between the original and changed flows.

whole process was then regenerated using exactly the same random numbers as before.

\subsection{Business cycles}

Empirical data already showed that long-term variations in risk exposure may have a very significant influence on the solvency ratio. This observation was reinforced by the theoretical model when a variation of the basic probabilities was introduced. The influence of the variations was assumed to meet the expected value of claims, which is one of the basic variables in the conventional risk theoretical formulae as follows:

$$
n(t)=n(0) \cdot\left(1+i_{g}\right)^{t} \cdot\left(1+z_{s}(t)\right)
$$

Here $n(t)$ is the expected number of claims in year $t, i_{g}$ is the real growth of the business (for the sake of simplicity it was assumed to be constant from year to year) and $z_{s}(t)$ is an auxiliary "cycle variable" which indicates the deviations of the average risk exposure from its normal value. The scale was defined so as to give a long-term mean value of zero for $z_{s}$.

As mentioned above, the cycle variable $z_{s}$ can be introduced into the model in different ways. The simplest way is to assume it to be deterministic, perhaps following the sine form

$$
z_{s}(t)=z_{m} \cdot \sin (\omega t+v)
$$


where $z_{m}$ is the amplitude of the wave and the coefficient $\omega$

\section{(4.3.3)}

$$
\omega=2 \pi / T_{s}
$$

is the frequency factor. Here $T_{s}$ is the wavelength and $v$ is a phase variable. More sophisticated models are achieved if several "sine formed" waves are composed together and a noise term is added; i.e. the methods of time series are applied.

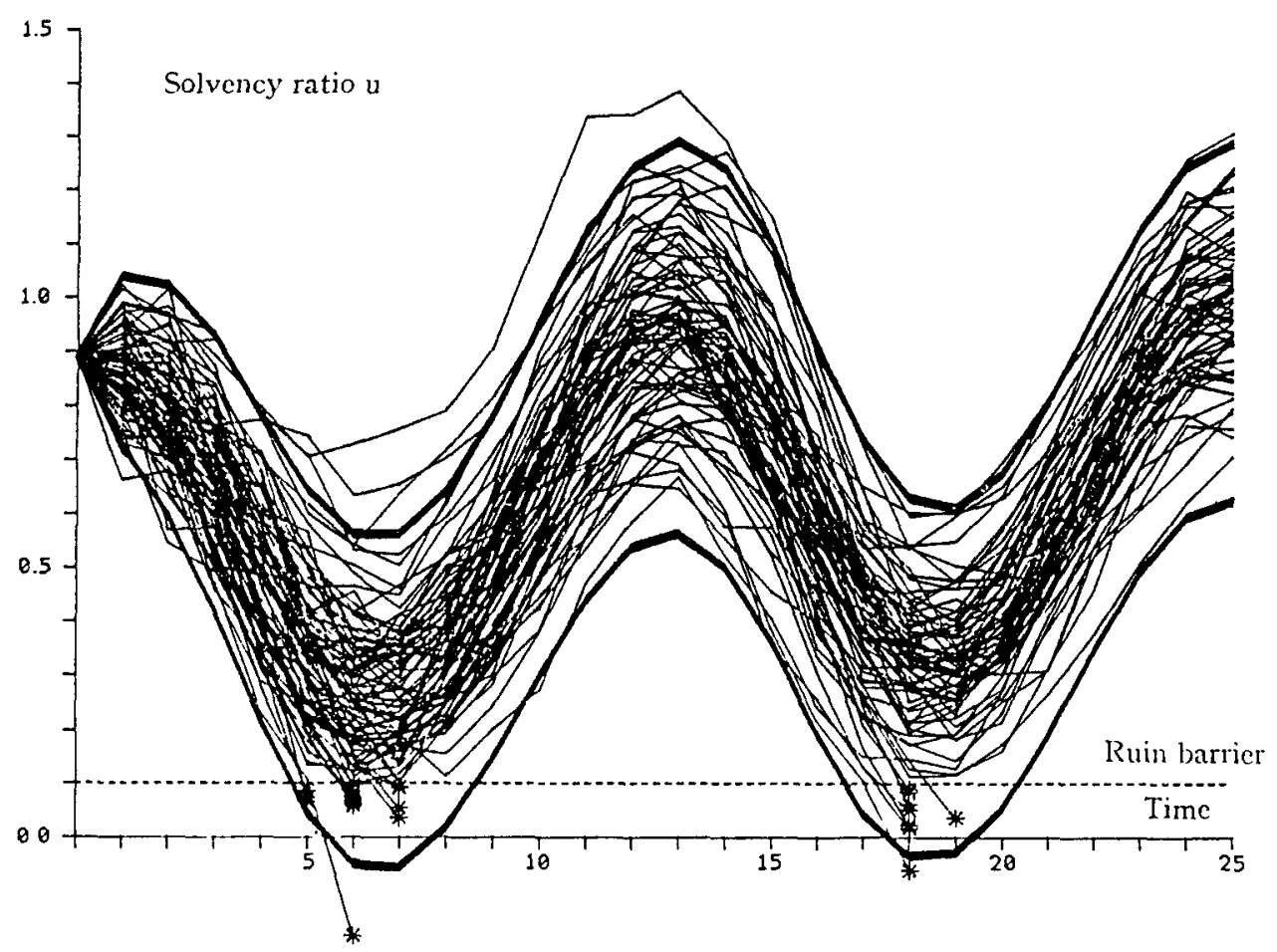

Fig. 10.

It can be seen from Fig. 10 how dramatically Fig. 2 changes when the business cycle is assumed. The amplitude ( $15 \%$ of the normal amount of claims) and wavelength (12 years) are no more than their empirical values.

Because our purpose was only to demonstrate the model, we are not going to discuss whether or not the results are realistic and what kind of conclusions can be drawn. The model can be developed by incorporating into it built-in dynamics. This could simulate the rational behaviour of the management when an unfavourable change in the solvency ratio is imminent, or the kind of action to be expected if the solvency ratio gets very high.

We will present another generalisation of the business cycle assumption. 
The phase variable $v$ in equation $(4.3 .2)$ can be randomized, the result being shown in Fig. 11.

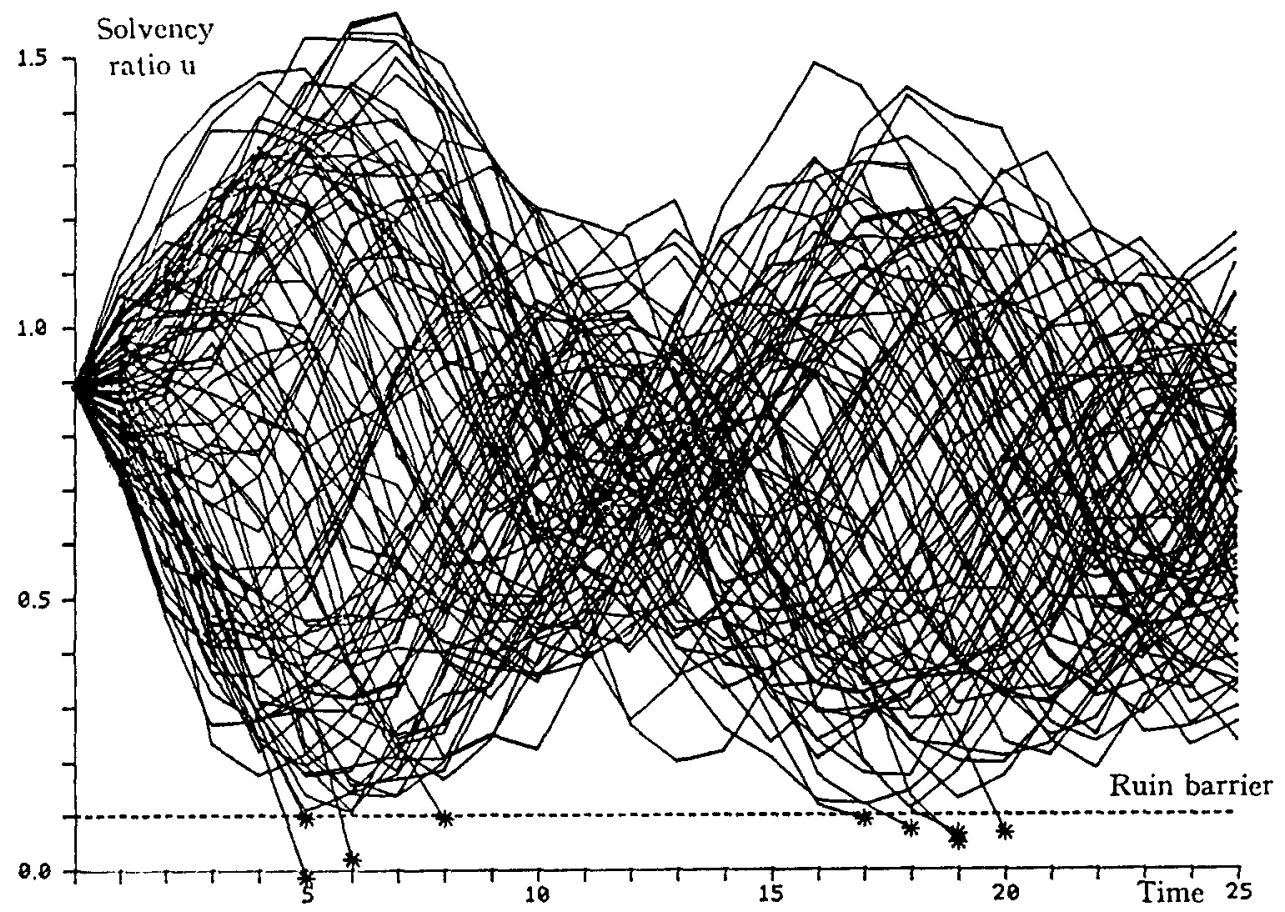

Fig. 11. The phase of the business cycle is randomised. ${ }^{*}=$ the insurers went brokc!

\subsection{Solvency profile}

Finally, yet another way to benefit from the model is presented. For any combination of the given values of the background factors the minimum solvency can be computed by the method mentioned in connection with Fig. 3. The minimum solvency ratio is first computed for each combination of background factors. The solvency ratio can be plotted as a horizontal column. In this way it is possible to show in one picture in a very concentrated shape how solvency depends on different value combinations of the background factors.

Fig. 12 is intended to illustrate the influence of the basic assumptions of the model.

First only the number of claims was assumed to be a random variable, whereas claim size and all other aspects were constant. As expected, the necessary minimum solvency ratio can be quite small, in our example $9 \%$ of the earned premiums on the company's own retention. 
Munimum solvency ratio $u=U / B$ in per cent

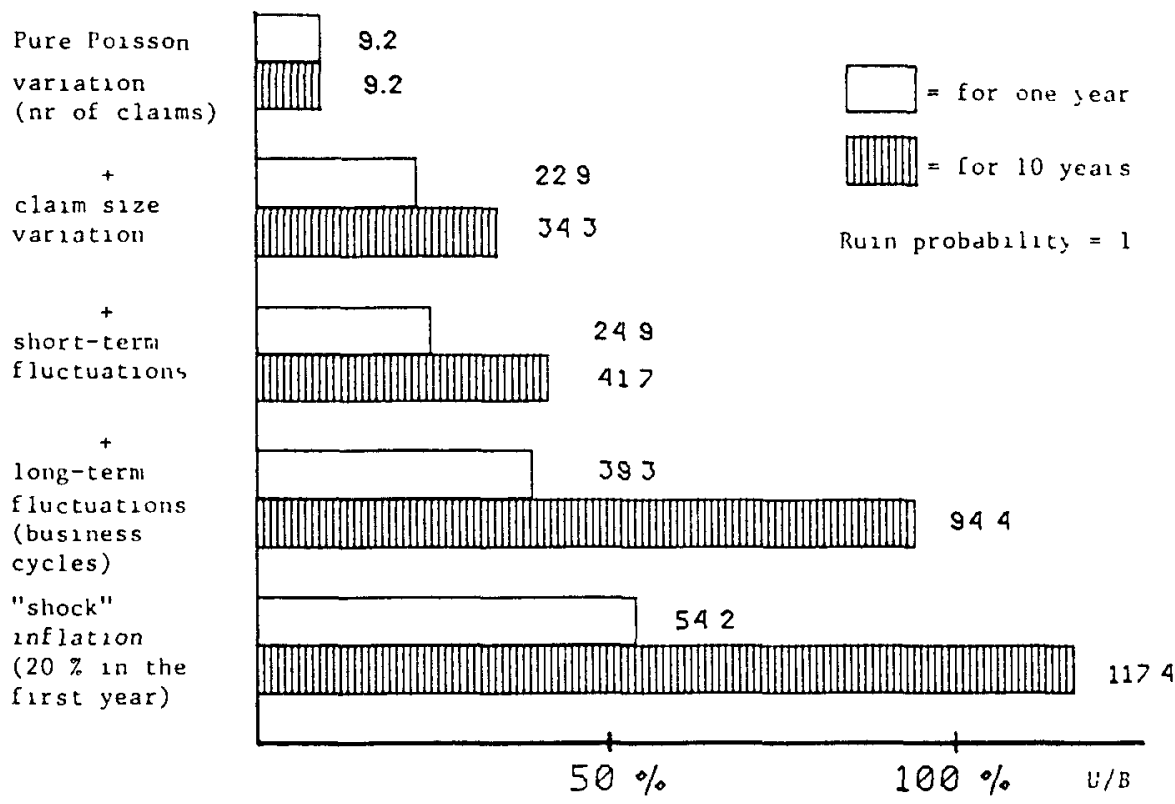

Fig 12 How does the minimum solvency ratio clepend on the different basic assumptions? (Ruin barrier $=0.1 . B$ ) Pure Poisson $=$ only the number of clains varies at random, no other element of the process Clan size $=\mathrm{m}$ addition, the size of individual claims also fluctuates. Short-term fluctuation $=$ in addition, the basic probabihties are also subject to short-term fluctuations Business cycles = long-term cycles in the basic probabilities are intioduced Shock inflation = finally a one-year shock inflation was assumed

The next step was to randomise the claim size, following which the short-span variations of basic probabilities were also introduced. Then, long-term business cycles were assumed, and finally a shock inflation impulse was added to the model (standard inflation $9 \%$, shock inflation rate $20 \%$ and lasting only the first year).

One-year and 10-year ruin probabilities are computed alternately.

The figure again shows how significant the assumption concerning business cycles is. The rate of inflation also affects the solvency condition greatly.

The computation was performed for a "standard insurer" which in size, portfolio mix, and otherwise corresponds to an average insurer in Finland.

In Fig. 13 numerous other background factors were experimented with by applying the same tcchnique. It is possible in this way to create a "solvency profile", which provides in one single picture at least a general concept of the degree of influence of many background factors. 


\section{Solvency profile}

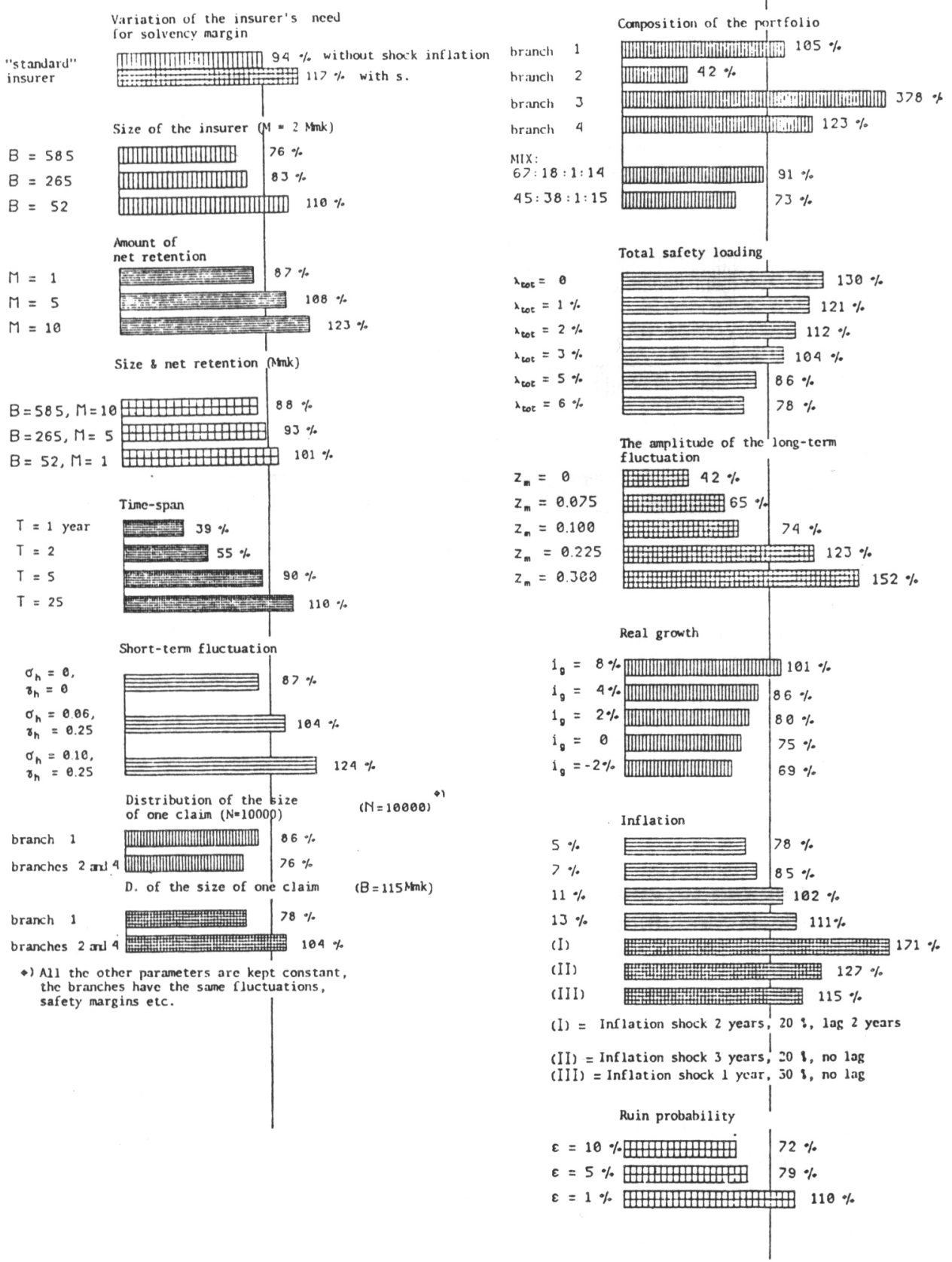

Fig 13 A solvency profile demonstrating how the solvency of an insurer depends on various background factors Time span to ycars Ruin barrier is o.1.B 
Monetary values such as premiums $B$ and net retention $M$ are given in millions of Fmk.

The portfolio mix was constructed by making use of four different typical sections and combining them in the proportions shown in the figure. Section I comprised a motor car, family property, etc., branches where the individual claim sizes are typically small and the risk exposure is not very sensitive to scasonal or other variations. Section 2 comprised industrial and marine insurance, etc., branches where the individual claim sizes can be large. Those branches where the risk exposure is very sensitive to short-term fluctuations, like forest insurance and credit insurance, were placed in section 3 . Section 4 comprised international reassurance.

This showed that differences in portfolio mix do not greatly affect solvency ratios. This is easily understood since normal reinsurance cuts off the risk tops. Irom the point of view of solvency the remaining distributions of the risks on the insurer's own retention are fairly similar.

Further details concerning this profile idea can be found in the forthcoming research report.

\subsection{Safety loading}

The evaluation of sufficient safety loading can be based on the equilibrium level and on the width of the stochastic bundle. The equilibrium level must be so high that the distance from the equilibrium level to the acceptable minimum level ( $\geq$ ruin barrier) is sufficient; i.e. it must be at least a half of the width of the stochastic bundle. This approach is in fact some kind of variant of the wcll-known standard deviation principle on the company level taking into account the business cycles and the other variations and factors inflation, growth, etc. If the NP-approximation is used in calculating the limits of the bundle then also the skewness of the distribution of the total amount of claims influences on the safety loading. (NP-approximation is described in the book by BEARD et. al. (1977). An extension of the method to the short tail of the distribution of the total claim amount will be presented in a forthcoming paper by T. PentikëInen.)

In the following tables there are given some few examples of appropriate safety loadings. These loadings are proportional to the gross premium on the insurer's own retention. Figures are calculated for a typical Finnish insurance company at $1 \%$ safcty level and with minimum level as zero. As said above also the business-cycles are taken into account. The notations are as follow:

$n=$ the expected number of claims/year in the first year;

$M=$ the net retention in millions of Fmk;

$B=$ the gross premium on the own retention in millions of Fmk;

$E u=$ the equilibrium level. 
TABLE 1

\begin{tabular}{|c|c|c|c|c|}
\hline \multicolumn{5}{|c|}{$\begin{array}{l}\text { Safety loading and the size and the net retention } \\
\text { of the insurer, when } i_{x}=0.09, i_{n}=0.085 \\
\qquad i_{g}=0.06 .\end{array}$} \\
\hline$n$ & $M$ & $B$ & $\lambda$ & $E u$ \\
\hline 5000 & 0.5 & 12 & 0.049 & 0.81 \\
\hline 10000 & 0.7 & 25 & 0.044 & 0.72 \\
\hline 20000 & 1.0 & 52 & 0.040 & 0.66 \\
\hline 40000 & 2.0 & 115 & 0.039 & 0.64 \\
\hline 80000 & 5.0 & 265 & 0.039 & 0.63 \\
\hline 160000 & 10.0 & 586 & 0.037 & 0.61 \\
\hline
\end{tabular}

The net retention is adjusted according to the size of the insurer in accordance with general practice. Then the safety loadings do not vary very nuch. Another example is given in table 2 fixing the size of the company but letting the rate of inflation and also the rate of interest vary.

TAlBLI: 2

\begin{tabular}{|c|c|c|c|c|}
\hline \multicolumn{5}{|c|}{$\begin{array}{l}\text { Safety loading and inflation, when } n=40000 \text {, } \\
\qquad M=2 \text { and } B=115\end{array}$} \\
\hline$i_{n}$ & $i_{\theta}$ & $i_{x}$ & $\lambda$ & $E_{u}$ \\
\hline 0.085 & 0.06 & 0.05 & 0.018 & 0.73 \\
\hline 0.085 & 0.06 & 0.07 & $0.03^{\circ}$ & 0.68 \\
\hline 0.085 & 0.06 & 0.09 & 0.039 & 0.64 \\
\hline 0.085 & 0.06 & 0.11 & 0.047 & 0.60 \\
\hline 0.085 & 0.06 & 0.13 & 0.054 & 0.57 \\
\hline 0.10 & 0.06 & 0.13 & 0.049 & 0.59 \\
\hline 0.06 & 0.06 & 0.09 & 0.049 & 0.60 \\
\hline
\end{tabular}

If the average inflation increases from $5 \%$ to $13 \%$ and the rate of interest doesn't increase then the safety loading and the premium level must be raised by $3.6 \%$ units in order to keep the same safety level. In addition one must do of course also the usual index-corrections. It is seen that although the safety loading increases the equilibrium level decreases.

\section{REFERENCES}

Beard R. E., Pentikäinen T. and E. Pesonen. (1977). Risk Theory, Chapman and Hall, London.

Becker, F. (1979). Analyse "on Zeitreihen der Kraftfahrtversicherung und Feuerversicherung in Abhängigkcit "on gesamtwivtschaftlichen Grössen, Vercin zur Förderung der Versicherungswissenschaft an der Universität Mannheim e.V.

Helten, E. (1977). Business cycles and insurance, The Geneva Papers on Risk and Insurance: Essays in the Economic Theory of Risk and Insurance. 
KArten, W. (1973). Zu Inhalt und Abgrenzung der Rïclsstellung fïr drohende Verluste aus schwebenden Geschäften in Versicherungsbilanzen, Versicherungswirtschaft 23, 73 .

IARTEN, W. (1975). Zur Begrïndung einer sachgevechten Schwankungsrückstellung, "Sorgen, versorgen, versichern", Festschrift für Heinz Gebhardt, Hans Kalwar, Karlsruhe.

KARTEN, W. (1980). The new "Schwankungsrüchstellung" in annual statements of German insurers. An application of the theory of risks, The Geneva Papers on IRisk and Insurance.

Pentikäinen, T. (1970). The fluctuation reserve as stipulated in the Finnish insurance company act of 1953, Bulletin of the Finnish Inswrance Information Centre.

Pentiküinen, T. (1975). A model of stochastic-dynamic prognosis, Scandinavian Actuarial Journal.

PentikäInen, T. (1978a), A solvency testing model building approach for business planning, Scandinavian Actuarial Journal.

PentikäInen, 'T. (1978b), Dynamic programming, an approach for analysing competition strategies, Astin Bulletin.

Transactions, 21 st International Congress of Actuaries, Zuirich \& Lausanne, 1980. 